$\mathbb{P}$ periodica polytechnica

\author{
Transportation Engineering \\ $38 / 2(2010) 99+104$ \\ doi: 10.3311/pp.tr.2010-2.07 \\ web: http://www.pp.bme.hu/tr \\ (c) Periodica Polytechnica 2010
}

RESEARCH ARTICLE

\section{Development strategy for sustainable transportation: towards intelligent systems}

\author{
Pál Michelberger / László Nádai
}

Received 2009-10-07

\begin{abstract}
In the paper there the structure and build-up of transportation systems, their development, and especially, the needs established by the society that motivate the continuous expansion of such systems will be outlined. The development is determined by the four participants ("components") of these systems, namely by the human beings, vehicles, infrastructure and regulations. The principal element of the process is man with his demands for mobility and transportation. These demands can be satisfied by manufacturers who produce the desired vehicles. The response time of manufacturers is much shorter than the development of infrastructure; however, the latter is also essential in order to serve transportation processes. The low flexibility of infrastructure is partly caused by the huge amount of necessary investment, and also by the complex ownership relations. The last element that usually appears with delay compared to the other three is the regulation system (laws, standards, specifications etc.), and it also expresses the needs of the society as long as the development - motivated by social demands - sometimes conflicts with other needs, i.e. the needs for safety or for the protection of environment. This contradiction finally closes the "control loop", and actuates the evolution of transportation systems.
\end{abstract}

\section{Keywords}

Intelligent transportation systems $\cdot$ sustainable development

Pál Michelberger

Department of Chassis and Lightweight Structures, BME, H-1111 Budapest Bertalan L. u. 2., Hungary

\section{László Nádai}

Computer and Automation Research Institute, Hungarian Academy of Sciences, H-1111 Budapest, Hungary

\section{Introduction}

The composition of traffic and transportation tasks was different in the course of history, and people used to endeavor to solve those problems in several ways [9]. Transportation is blessing in one's eye that is an important resort to maintain the existence of mankind, but others see it as curse that ruins the environment and endangers the biological entity of humanity. This problem should be examined objectively, without prejudice. The object we propose in not the reconciliation of contradicting opinions, nor the quest for compromise, but the demonstration of factual advantages and disadvantages and to outline the challenges of the near future that should be solved. Society, technology and environment are the three main - simultaneously active and passive - characters of transportation systems, but only the first two can be influenced by us in order to solve the imperative lessons. Environment should be protected by society and technology for the good of society [6].

\section{Interaction between society, environment and tech- nology}

Traffic and transportation had been supplying mankind already in prehistoric times. Primary materials (food, water, clothes, and fuel) necessary to sustain human life could rarely be found in the direct vicinity of habitation, they should be transported from the place of production. Transportation problems are even more categorical regarding secondary (tasks corresponding to profession, occupation and administration) and tertiary (recreational) needs, and also the composition of those needs was constantly changing in the course of history, and nowadays it is very hard to distinguish between them. In this way e.g. hunt that originally supplied primary needs transformed to a tertiary sport; or the travel of a hotel employee to the workplace satisfies both his secondary and the guests' tertiary needs. In the past not only the nature and proportion of transportation tasks had been changed, but also the quantity of them was shifted about. The growth of traffic and transportation is unstoppable and continuous, even wars or economic crisis do not alter this trend, only the composition of products and travelers varies [1]. 


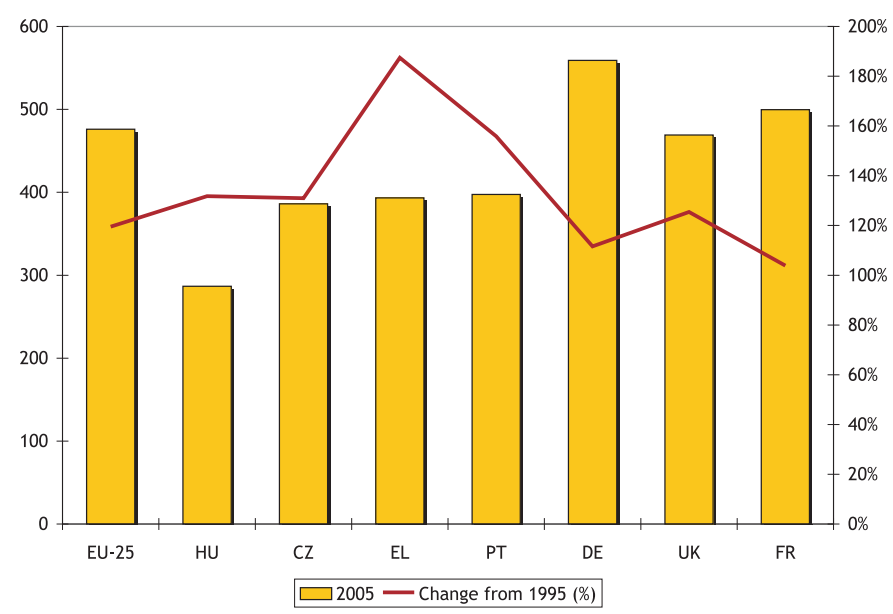

Fig. 1. Number of passenger cars per 1000 inhabitants in the European Union

Probably the most representative parameter of the quantitative growth of transportation is the number of operating vehicles worldwide. Nowadays there are 800 million vehicles on the roads and this number increases 40 millions per year, but it is very far from saturation. Considering the endowment in the EU [2], for 6 billion people there should be about 3 billions of vehicles, that is a quadruple of the present amount, but the economic and technological conditions are far from reality, cf. Fig. 2 .

The decisive element of transportation is the social need, but the development is also affected by environmental constraints and technological solutions. All of the three participants play active roles and take effects on the other two, and also the actual realization of transportation reacts on society, environment and technology. Therefore all three elements both active and passive, will be investigated in the subsequent sections.

\subsection{The active and passive role of society in transportation} Active roles (needs):

- Needs (primary, secondary and tertiary) of the society determine the fundamental tasks that should be performed by transportation.

- Members of society play active roles in transportation processes as drivers, passengers or traffic controllers.

- A notable portion of society (about 16\%) produces (designs, manufactures, operates and maintains) the infrastructure and vehicles necessary for transportation.

Passive roles (suffering):

- Accidents (in Hungary there are more than 2000 deadly accidents per year).

- Depletion of environment, usually localized near to highways and cities, and some places dominates the environmental pollution.

- Saturation of roads that can be a self-embarrassment of transportation in some periods.
2.2 The active and passive role of environment in transportation

Active roles (geography):

- Geographic environment essentially determines the locality of raw material inventories and human settlements, therefore the start- and endpoints of transport routes.

- Geographic situation (river valleys, gulfs suitable for docking etc.) more or less localizes the possible lines that can be deviated only by extraordinary expenses.

Passive roles (degradation):

- All transport lines decrease the field covered by vegetation (highways in OECD countries cover approximately 150000 $\mathrm{km}^{2}$ with concrete and asphalt that is equal to one and a half of the Hungarian territory).

- Accidents directly, emitted poisonous materials indirectly damage the fauna and endanger the subsistence of biodiversity. The network of connected lanes partitions the natural territories, and formulates too small and insulated regions. This leads to inbreeding, finally to the degradation of fauna.

\subsection{The active and passive role of technology in transporta- tion}

We use technology in broader sense, i.e. consider lanes and theirs attachments, vehicles, infrastructure, and all the logistics that play role in the control and regulation of traffic. In this triplet (lane, vehicle, logistics) there were remarkable changes in emphasis during the times. Initially transportation was dominated by lanes, but gradually vehicles get into the foreground. However, the future expectedly will belong to logistics and informatics [4]. This shift of the center of gravity does not mean that the other elements will disappear, because the three aspects of technology mutually affect each other. The modernization of vehicles (e.g. increase of final speed) raise new requirements to lane construction, integrated logistics systems require regulation and control that also involve lanes and vehicles etc.

Active roles (problem solving):

- Vehicle technology is one of the catalysts of the development of technical sciences. Almost all of statics was initiated by the construction of lanes and bridges, and modern thermodynamics was highly influenced by the development of vehicles. The connection between logistics and informatics is too fresh, but their interaction is prosperous without doubt.

- Vehicle industry revolutionized technology twice: in the beginning of the Twentieth Century the production line introduced by Henry Ford supported the mass permeation of automobiles. And also, at the end of the century, robotized individual production makes possible the shipment of numerous variants of the same vehicle type in an arbitrary sequence. 
- Transportation (and vehicle production) is one of the top employers in the developed world, directly or indirectly it employs approximately $16 \%$ of the population able to work. Every workplace in vehicle industry creates three other jobs in the background sector, or reversely, any layoff in vehicle industry results in three other discharges in the background sector.

Passive roles (consumption and load):

- Transportation is the most important consumer of raw materials and energy. The recycling of materials is unsolved yet, only $30 \%$ gets back into production, the other $70 \%$ loads the environment. The efficiency of energy utilization is very low, only $10 \%$ of the energy content of exploited petroleum is utilized as mechanical work in transportation systems.

- Lanes and vehicles occupy a certain amount of space, and even by their normal operation they destruct the environment.

- In saturated state transportation can be self-locking.

\section{Tasks to be solved}

The sustainability of transportation is an inevitable medium to maintain the existence of society. It plays a positive role by increasing life quality through the better supply of several needs, at the same time - by the numerous accidents, the pollution of environment, and the wastage of materials and energy - it plays a very negative role, too. This contradiction can only be resolved by "running forward", by the development of science and technology. The main tasks can be counted according to negative impacts.

- The number of accidents should be decreased.

- The pollution of environment should be decreased.

- The specific energy consumption should be decreased.

- The specific material consumption should be decreased.

The service data of different transportation sectors are essentially different from each other. The most favorable indicators concerning energy belong to water transportation, air traffic is worse by several orders of magnitude. Similar observations apply to the specific accidental indicators; the ratio of accidental death per traveled distance is four to eight times higher in road transport than in railways. The consumption of space is also a serious factor: a two-track railway line occupies 14 meters, compared to the 34 meters occupied by a four-track highway.

All of the above indicate that the sustainability of an efficient transportation system is not only a scientific or technological question, but also an economic and political one that requires very complex comparisons. If one reviews the different $R \& D$ efforts all over the world it should be realized that the scientific solutions are already elaborated. However, scientific discoveries will transform into technological solutions only if the service
Tab. 1. The development cycle of transportation systems

\begin{tabular}{ll}
\hline Field & Activities \\
\hline Science & Research \\
Technology & Development \\
Industry & Design \\
& Production \\
Economy & Commercialization (selling, service, maintenance, repair) \\
Society & Reflections (legal, ecological, ethical) \\
\hline
\end{tabular}

dependability, the equipment size and the operating speed are suitable for practical applications.

Moreover, each technological solution can be taken into production and industrial application if the companies in concern possess the necessary professional workforce, manufacturing equipment and machines. Finally, all of these are too short for the introduction to market, the solution should also be economic; otherwise the product or service will not be competitive. A scientifically discovered, technologically elaborated, and industrially economic solution is marketable only if it meets the real needs of the society, that is a most difficult and indefinable idea, because it is a mixture of taste, tradition, habits, prejudice, legal regulation and routines.

The above described fields and the corresponding activities are listed in Table 1

Science and technology can exactly be fitted to research and development, but the other fields and activities can hardly be separated. It is obvious that a study like this one covers mainly scientific and technological questions, since those fields - and the specific solutions corresponding to them - can easily be reviewed, presented and discussed.

\section{Solutions}

The challenges outlined above can be solved, since science and technology guarantee the necessary tools. The so-called "intelligent vehicle" has appeared in transportation. In the most common case (see Fig. 2) individual functions are controlled (e.g. ABS, EBS, fuel feeding). In a more advanced implementation several functions are controlled together (e.g. the brake and the steering wheel). The final goal is the integrated control of all vehicle functions, moreover, the connection of vehicles to each other and to the environment.

Moreover, research and development has overrun vehicles and lanes, the aim is the total control and automation of transportation systems and the optimization of economy and the protection of environment, see Fig. 3 .

However, the more global the objective, the more societal conflicts obstruct the realization (economic counter-interest, the lack of legal regulation, the share of liability, psychological problems etc.). The hardness of vehicle automation can be demonstrated by the change of division of labor between driver and the intelligent vehicle system, see Figure 4

ITS applications are structured below according to the structure used by the U.S. Department of Transportation [13]. The 


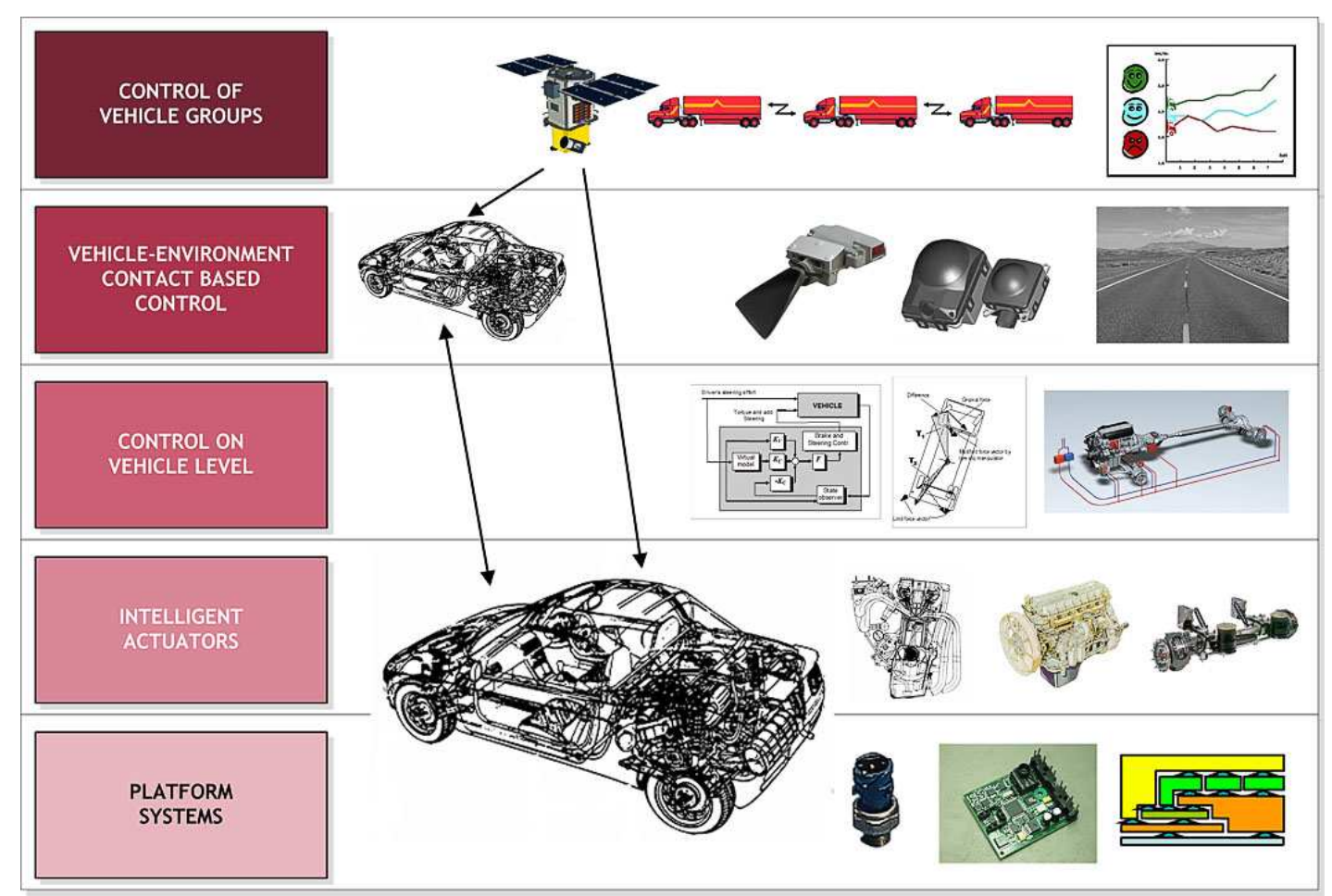

Fig. 2. The levels of intelligent transportation systems

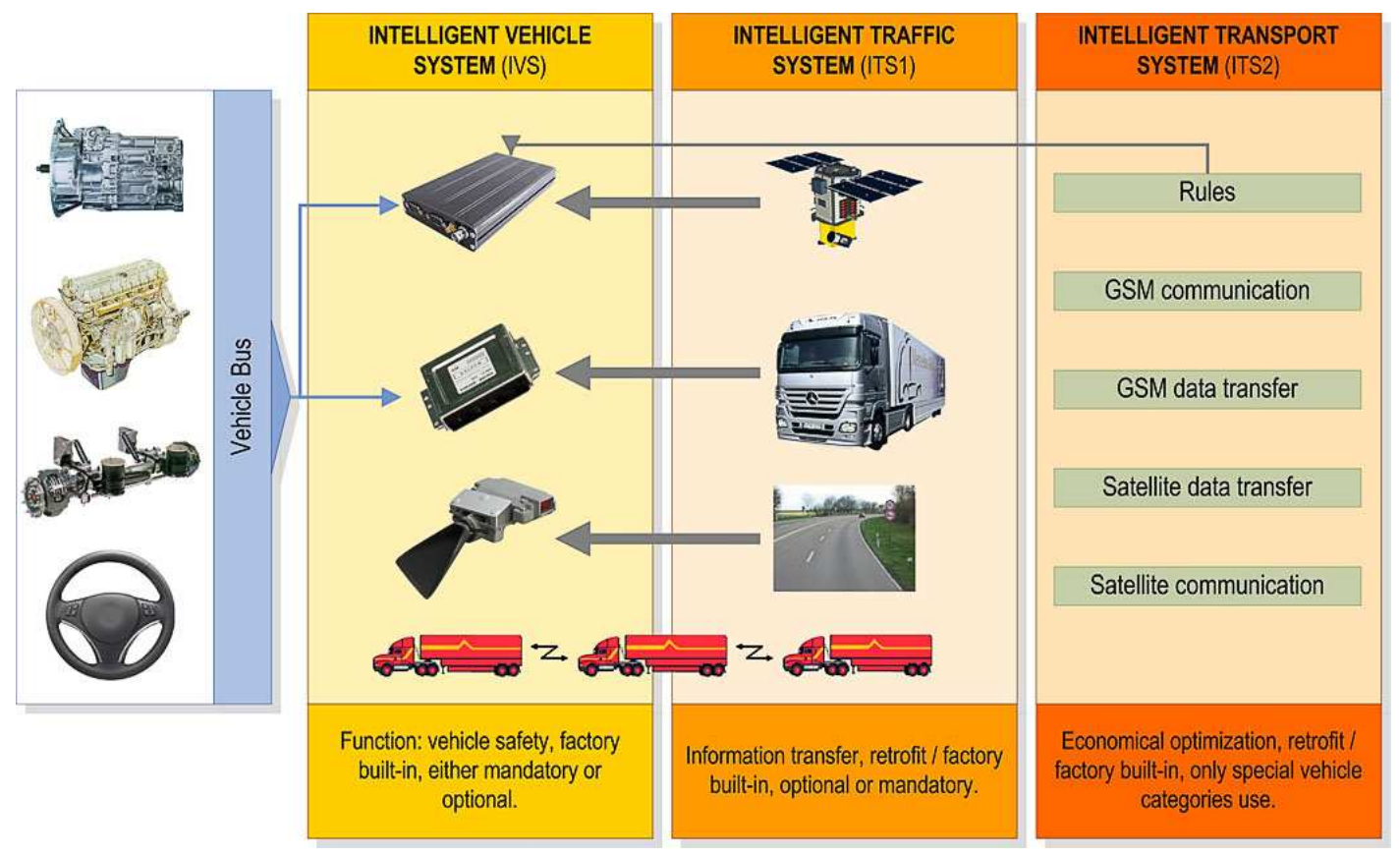

Fig. 3. ITS is interdisciplinary and complex

ITS application areas are divided into two categories: intelligent infrastructure and intelligent vehicles. The classification is based on the focus of the application not necessarily the place of the implementation itself.

Intelligent infrastructure consists of infrastructure elements that are able to collect data about traffic, specific fleets, roadway conditions, weather, passengers or even freight. After processing this information the infrastructure uses different communication channels to forward information to interested parties. The communication channels include dynamic message signs, high- way advisory radio, in-vehicle signing, Internet websites, telephone hotlines, as well as television or specialized channels for specific set of vehicles or regulatory agencies. The services provided by intelligent infrastructure systems vary in a broad range including smoothing the flow of traffic along travel corridors, disseminating important information about travel conditions to travelers, traffic surveillance systems, controlling the impact of congestion at stadiums or convention centers, computer-aided dispatch systems, remote vehicle and facility surveillance systems, reduction of the effects of incident-related congestion, 


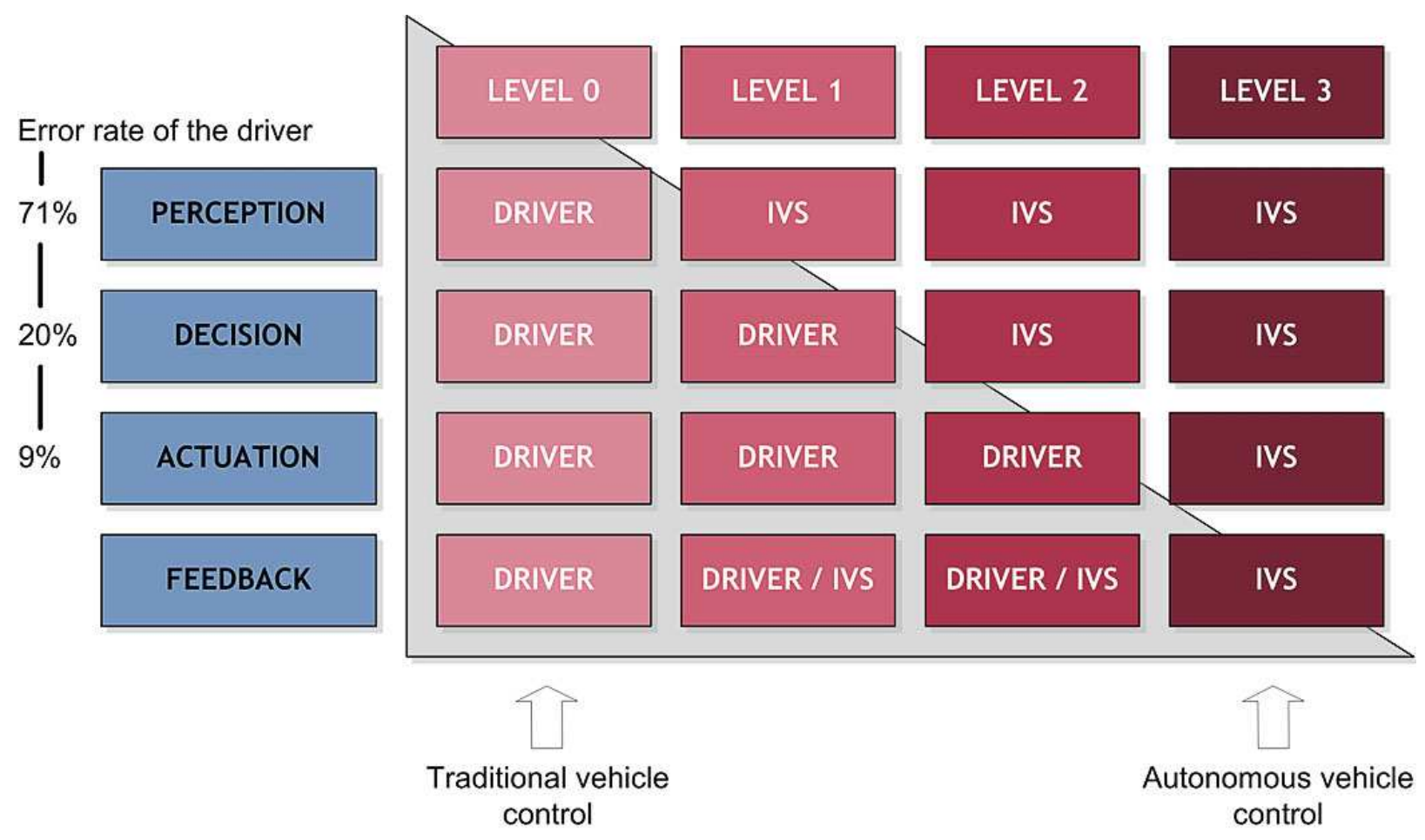

Fig. 4. The autonomy of vehicles is not only a technological question

hazardous materials management, the deployment of emergency medical services, and large and small-scale emergency response and evacuation operations, electronic payment systems, traveler information applications, decision support systems, crash prevention and safety systems, integrated management of maintenance fleets, road weather information systems, winter maintenance technologies, electronic registration and permitting programs, electronic exchange of inspection data between regulating agencies for better inspection targeting, electronic screening systems, and several applications to assist operators with fleet operations and security, tracking of freight and carrier assets such as containers and chassis, and improvement of the efficiency of freight terminal processes, drayage operations, and international border crossings.

The category intelligent infrastructure includes following application areas:

- Arterial management systems

- Freeway management

- Transit management

- Incident management

- Emergency management

- Electronic payment

- Traveler information

- Information management

- Crash prevention and safety
- Roadway operation and maintenance

- Road weather management commercial vehicle operations

- Intermodal freight

Intelligent vehicles are equipped with several sensors and on-board computers that provide real-time information for the driver about environmental conditions or relevant incidents and facilitate safe driving during adverse conditions. The category intelligent vehicles consists of following application areas:

- Collision avoidance systems

- Driver assistance systems

- Collision notification systems

An overview of ITS is given via the architecture diagram in Fig. 5 .

\section{Conclusions}

Informatics is a perfect tool in the hands of a scientist or an engineer. The number of accidents can be reduced, dangerous situations can be avoided, fuel consumption can be cut back, an optimized combined transportation system can be constructed; moreover, different goals can be fulfilled: minimal costs, minimal emission rates or minimal transportation times can be achieved. All tools are ready, but will the society accept the optimal solution? Will anyone change the passenger car (or motorcycle) to public transport? Will people surrender unnecessary transportation of goods, or henceforward distribute the cooperating partners according to only one aspect (local wages)? 


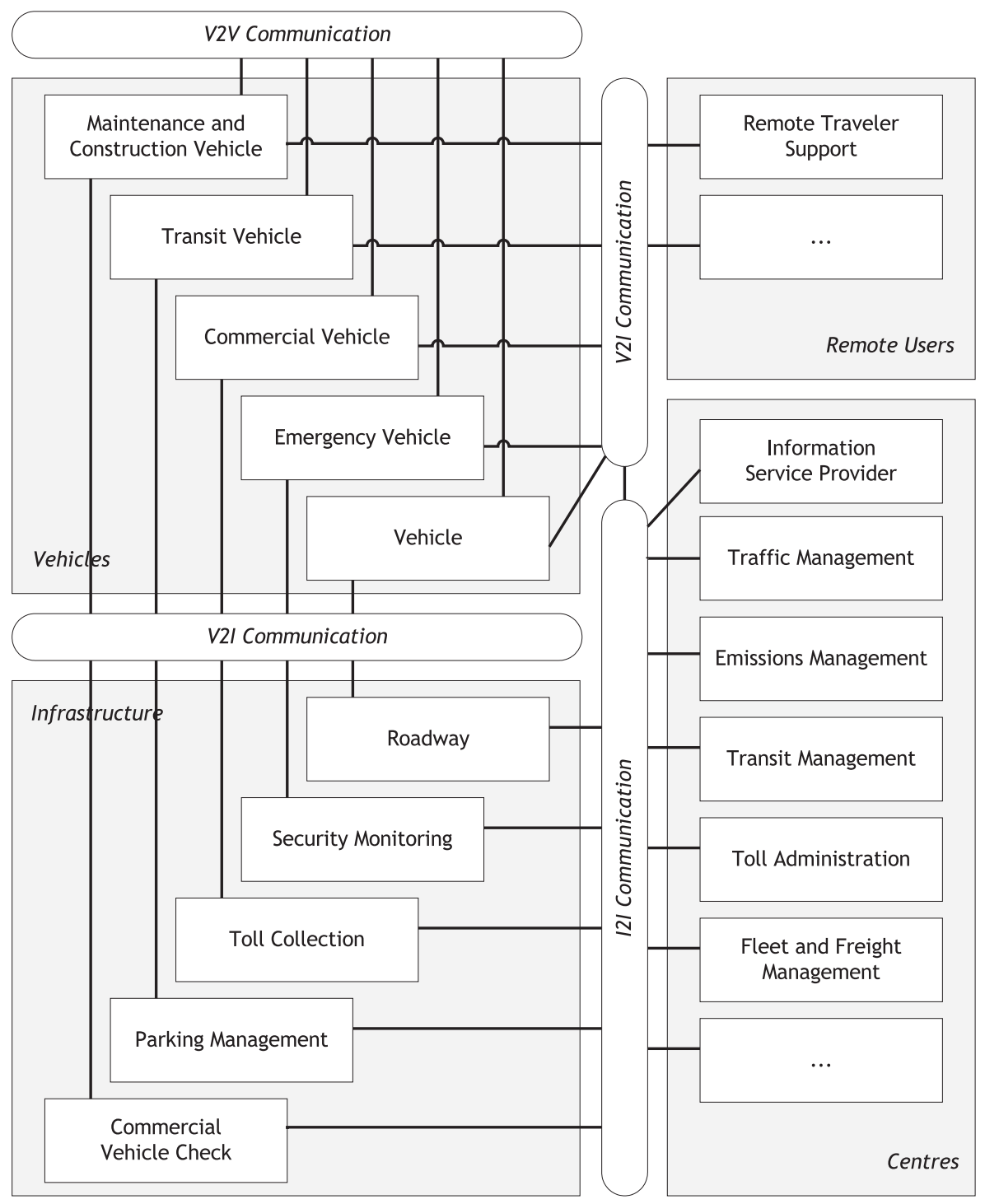

Fig. 5. An overview of Intelligent Transportation Systems

\section{Acknowledgement}

This research work has been partially supported by the Pázmány Péter Program of the National Office for Research and Technology through the Advanced Vehicles and Vehicle Control Knowledge Center, and the Transportation Informatics and Telematics Knowledge Center.

This work is connected to the scientific program of the " Development of quality-oriented and harmonized R+D+I strategy and functional model at BME" project. This project is supported by the New Hungary Development Plan (Project ID: TÁMOP-4.2.1/B-09/1/KMR-2010-0002).

\section{References}

1 Barker T, Gerhold D, The Rise and Rise of Road Transport, 1700-1990, Cambridge University Press, England, 1995.

2 European Commission, Europe in figures - Eurostat yearbook, available at http://ec. europa.eu/eurostat Chapter 9: Transport.

3 European Communities White Paper, European transport policy for 2010: time to decide, Luxembourg, 2001.

4 Kasilingam R G, Logistics and Transportation: Design and Planning, Kluwer Academic Publisher, Dordrecht-London, 1998.

5 Lepsényi I, Structural changes in local and international vehicle manufacture, Gépipar 36 (2005), no. 11, 1-4. (in Hungarian).
6 Maibach M, Schreyer C, Sutter D (INFRAS); H.P. van Essen, Boon B H, Smokers R, Schroten A (CE Delft); Doll C (Fraunhofer Gesellschaft - ISI);, Pawlowska B, Bak M (University of Gdansk), Handbook on estimation of external cost in the transport sector, Delft, CE, 2007.

7 Michelberger P, Transportation and shipment - the interaction of society, technology and environment, Közúti és Mélyépítési Szemle 49 (1999), no. 12, 534-536. (in Hungarian).

8 Palkovics L, Automobility and science, 2006. (manuscript).

9 Papageorgiou M (ed.), Concise Encyclopedia of Traffic $\mathcal{E}$ Transportation Systems, Pergamon Press, Oxford, England, 1991.

10 Péter T, Bokor J, Modeling and Control of Vehicle Traffic Systems, A jövő jármúve 1 (2006), no. 1-2, 19-23. (in Hungarian).

11 _ Interconnection Hypermatrix for Non-linear Modeling of Great Road Transport Networks, A jövő jármúve 1 (2007), no. 3-4, 16-21. (in Hungarian).

12 Péter. T, Stróbl A, Fazekas S, Process Analysis by Software for Optimizing Great Road Transport Networks, A jövő jármúve 2 (2008), no. 1-2, 37-40. (in Hungarian).

13 Research and Innovative Technology Administration, U.S. Department of Transportation, available at http://www.its.dot.gov 